\title{
Hypoxanthine, Xanthine, and Uric Acid Concentrations in the Cerebrospinal Fluid, Plasma, and Urine of Hypoxemic Pigs
}

\author{
JAN PETER POULSEN, STEPHANIE ØYASÆTER, JON SANDERUD, TORLEIV OLE ROGNUM, \\ AND OLA DIDRIK SAUGSTAD \\ Institute for Surgical Research [J.P.P., J.S.], Institute for Pediatric Research [S.Ø., O.D.S.], Institute of Forensic \\ Medicine [T.O.R.], and Department of Pediatrics [O.D.S.], University of Oslo, The National Hospital, \\ N-0027 Oslo 1, Norway
}

\begin{abstract}
The concentrations of hypoxanthine, xanthine, and uric acid in plasma and cerebrospinal fluid (CSF), as well as the urinary output of hypoxanthine and xanthine, were measured in four groups of pigs (three groups with different degrees of hypoxemia and one control group). During hypoxemia with arterial $\mathrm{O}_{2}$ tension between 2.1 and $3.0 \mathrm{kPa}$ |group 1, fractional inspired oxygen $\left(\mathrm{FiO}_{2}\right)$ $=0.08$, hypoxanthine increased in CSF from a mean basal value of 18.1 to $39.3 \mu \mathrm{mol} / \mathrm{L}$ at death $(p<0.02)$, in plasma from 25.4 to $103.6 \mu \mathrm{mol} / \mathrm{L}(p<0.05)$, and in urine from 21.3 to $87.1 \mathrm{nmol} / \mathrm{kg} / \mathrm{min}(p<0.02)$. Xanthine changed in a similar way: in CSF from 4.0 to $10.6 \mu \mathrm{mol} / \mathrm{L}(p<0.02)$, in plasma from 0.7 to $48.1 \mu \mathrm{mol} / \mathrm{L}(p<0.02)$, and in urine from 4.0 to $12.6 \mathrm{nmol} / \mathrm{kg} / \mathrm{min}(p<0.05)$. Uric acid increased in CSF from 2.7 to $11.6 \mu \mathrm{mol} / \mathrm{L}(p<0.05)$, and in plasma from 15.4 to $125.0 \mu \mathrm{mol} / \mathrm{L}(p<0.02)$. During hypoxemia with arterial $\mathrm{O}_{2}$ tension between 3.0 and 4.0 $\mathrm{kPa}$ (group 2, $\mathrm{FiO}_{2}=0.11$ ), hypoxanthine increased in the CSF from 14.7 to $42.9 \mu \mathrm{mol} / \mathrm{L}(p<0.02)$. Plasma hypoxanthine increased from 20.3 to a maximum of $44.1 \mu \mathrm{mol} /$ $\mathrm{L}(p<0.02)$, but decreased to initial values by the time of death. The urinary excretion of hypoxanthine increased from 13 to $54 \mathrm{nmol} / \mathrm{kg} / \mathrm{min}(p<0.02)$. Xanthine increased in the CSF from 3.9 to $13.3 \mu \mathrm{mol} / \mathrm{L}(p<0.02)$, in plasma from 0.6 to $36.6 \mu \mathrm{mol} / \mathrm{L}(p<0.02)$, and in urine from 6 to $25 \mathrm{nmol} / \mathrm{kg} / \mathrm{min}(p<0.02)$. Uric acid increased in CSF from 3.1 to $16.3 \mu \mathrm{mol} / \mathrm{L}(p<0.02)$, and in plasma from 15.3 to $208 \mu \mathrm{mol} / \mathrm{L}(p<0.02)$. During milder hypoxemia with arterial $\mathrm{O}_{2}$ tension between 4.3 and $5.6 \mathrm{kPa}$ (group 3, $\mathrm{FiO}_{2}=0.14$ ), or in the control group (group $4, \mathrm{FiO}_{2}=$ 0.21 ), neither of the metabolites changed significantly. (Pediatr Res 28: 477-481, 1990)
\end{abstract}

\section{Abbreviations}

CSF, cerebrospinal fluid

$\mathrm{FiO}_{2}$, fractional inspired oxygen

$\mathrm{PaO}_{2}$, arterial $\mathrm{O}_{2}$ tension

$\mathrm{PaCO}_{2}$, arterial $\mathrm{CO}_{2}$ tension

Hypoxia is a common insult during the perinatal and neonatal period. Several biochemical measurements can be done to eval-

Received January 15, 1990; accepted June 5, 1990.

Correspondence and reprint requests: Dr. Jan Peter Poulsen, Institute for Surgical Research, University of Oslo, The National Hospital, N-0027 Oslo 1, Norway.

Supported by the Norwegian Women's Public Health Association, the Norwegian Research Council for Science and the Humanities, The Lærdal Foundation for Acute Medicine, and Odd Fellow Medical Research Foundation. J.P.P. is a Research Fellow with The Norwegian Cancer Society. uate hypoxia, but to correlate a biochemically measured value with the outcome of hypoxia is difficult. Measurements of the purine metabolite hypoxanthine can be used as an indicator of hypoxia (1). During tissue hypoxia, elevated hypoxanthine levels have been found in plasma $(2-5), \operatorname{CSF}(6,7)$, and urine (8). However, no clear definition of clinical hypoxia is available, and many authors do not distinguish between the terms hypoxemia and hypoxia, which adds to the confusion. Our meaning of hypoxia has previously been described (1). In our study the pigs were subjected to hypoxemia. We define hypoxemia as deficient oxygenation of the blood. Hypoxemia may, however, not necessarily lead to tissue hypoxia.

To further assess the usefulness of hypoxanthine as a biochemical marker of hypoxia, we report how three degrees of hypoxemia in young pigs influence the level of hypoxanthine, xanthine, and uric acid in the CSF and plasma, as well as the pigs' urinary excretion of hypoxanthine and xanthine.

\section{MATERIALS AND METHODS}

Approval. The local hospital's ethical committee for animal studies approved these experiments.

Animal model. The animal model was similar to that previously described (9). Twenty-two young pigs of either sex (the males had been castrated shortly after birth) weighing $17-22 \mathrm{~kg}$ (mean $18.1 \mathrm{~kg}$ ) were used. They were anesthetized with an intraperitoneal injection of sodium pentobarbital $(30 \mathrm{mg} / \mathrm{kg})$. An i.v. line was established through an ear vein, and a continuous infusion of Ringer acetate $(10 \mathrm{~mL} / \mathrm{kg} / \mathrm{h})$ was given during the experiment. A further $100 \mathrm{mg}$ of sodium pentobarbital was given i.v. if necessary every $30 \mathrm{~min}$. A cuffed tube was placed in the trachea via a tracheostomy. Artificial ventilation was given by a ventilator (Servo-ventilator 900B, Elema-Schønander, Stockholm, Sweden). Ventilation rate and tidal volume were adjusted until $\mathrm{PaCO}_{2}$ ranged between 4 and $5.3 \mathrm{kPa}(30-40 \mathrm{~mm} \mathrm{Hg})$. No further adjustments of the ventilator were done during the hypoxemic period.

A midline suprapubic laparotomy was performed and a urinary catheter was placed in the bladder for measuring diuresis and urinary hypoxanthine and xanthine.

Polyethylene catheters were inserted into a femoral artery and a femoral vein. The arterial catheter was used for taking blood samples and for measuring blood pressure continuously with a strain gauge transducer, Gould recorder 2600S (Gould Inc. Recording Systems, Cleveland, $\mathrm{OH}$ ). The venous catheter was used for giving Ringer acetate plus additional sodium pentobarbital.

The pigs were divided into three hypoxemic and one control group. Seven animals were made hypoxemic by artificial ventilation with $8 \%$ oxygen in nitrogen $\left(\mathrm{FiO}_{2}=0.08\right)$ (group 1). Seven 
animals were ventilated with $11 \%$ oxygen $\left(\mathrm{FiO}_{2}=0.11\right)$ (group 2). Five animals were ventilated with $14 \%$ oxygen $\left(\mathrm{FiO}_{2}=0.14\right)$ (group 3), and three animals were ventilated with room air $\left(\mathrm{FiO}_{2}\right.$ $=0.21$ ), serving as normoxemic controls (group 4). The oxygen concentrations were measured continuously in all pigs during the experiments with a Dameca OM 831 oxygen monitor (Dameca Inc., Copenhagen, Denmark).

During hypoxemia with $\mathrm{FiO}_{2}=0.08$, the $\mathrm{PaO}_{2}$ remained between 2.1 and $3.0 \mathrm{kPa}(15.8-22.5 \mathrm{~mm} \mathrm{Hg})$. This degree of hypoxemia lasted until the animals died after a mean of $170 \mathrm{~min}$ (range 120-240 min). During hypoxemia with $\mathrm{FiO}_{2}=0.11$, the $\mathrm{PaO}_{2}$ remained between 3.0 and $4.0 \mathrm{kPa}(22.5-30 \mathrm{~mm} \mathrm{Hg})$, and these pigs died after a mean of $283 \mathrm{~min}$ (range $165-445 \mathrm{~min}$ ). During the mildest hypoxemia $\left(\mathrm{FiO}_{2}=0.14\right)$, the $\mathrm{PaO}_{2}$ remained between 4.3 and $5.6 \mathrm{kPa}(32.5-42 \mathrm{~mm} \mathrm{Hg})$. All animals tolerated this degree of hypoxemia for $480 \mathrm{~min}$, after which they were killed with an i.v. overdose of sodium pentobarbital. The pigs in the control group were observed from 185 to 480 min and then killed. During artificial ventilation, $1 \mathrm{~mL}$ of pancuronium bromide (Pavulon $2 \mathrm{mg} / \mathrm{mL}$, Organon Teknika, Boxtel, Netherlands) was given i.v. every $30 \mathrm{~min}$ to prevent muscular contractions, which may lead to artificially high hypoxanthine levels (10).

Blood samples. Arterial blood samples were taken after a stabilizing period of at least $1 \mathrm{~h}$ after surgery but before hypoxemia was initiated (basal values). During hypoxemia, blood samples were withdrawn at 5, 15, and $30 \mathrm{~min}$ and then every 30 min as long as the experiment lasted. Blood gases were measured with an AVL 945 Automatic Blood Gas System (AVL Biomedical Instruments, Schaffhausen, Switzerland). Another $\mathrm{mL}$ of blood was taken into heparinized tubes before hypoxemia and then every $30 \mathrm{~min}$ for hypoxanthine and xanthine analyses. In groups 1 and 2, uric acid was also measured in the blood samples. The withdrawn blood was immediately replaced with an equal volume of sterile $\mathrm{NaCl}(0.9 \%)$.

Sampling of CSF. A lumbar puncture needle was placed in the cisterna magna during the experiment. Two hundred to 400 $\mu \mathrm{L}$ of CSF were drawn from this needle at the same sampling times as previously described for blood hypoxanthine.

The samples of blood and CSF were immediately centrifuged for $10 \mathrm{~min}$ at $1800 \times \mathrm{g}, 4^{\circ} \mathrm{C}$, to remove cells. The plasma and clear CSF were transferred into polypropylene tubes and frozen at $-20^{\circ} \mathrm{C}$ until the time of analysis.

Sampling of urine. Urine was continuously collected into a catheter bag during the experiments. Before hypoxemia and then every $30 \mathrm{~min}$ as long as the experiment lasted, the amount of urine was measured and a 1-mL sample was frozen for later measurements of hypoxanthine and xanthine. The concentrations were related to diuresis, and the amount excreted per min per $\mathrm{kg}$ body weight was calculated.

Analysis of hypoxanthine, xanthine, and uric acid concentrations. The hypoxanthine and xanthine levels in CSF, plasma, and urine were analyzed using an HPLC method $(11,12)$.

The plasma samples were prepared by centrifugation for 30 min through a filter with $30000 \mathrm{~mol}$ wt cut-off (YMT-filter, MPS-1 System, Amicon Corp., Danvers, MA).

Using a syringe, the other fluids were passed through a 4-mm Millex-HV $\mathrm{H}_{4}$ unit with $0.45-\mu \mathrm{m}$ pore size (Millipore Corp., Bedford, MA).

The chromatography was performed on a reversed-phase column $(0.45 \times 15 \mathrm{~cm})$ of $5-\mu \mathrm{m}$ material (Pecosphere-5C C18, Perkin-Elmer Corp., Norwalk, CT). The mobile phase used for the chromatography was $0.005 \mathrm{M} \mathrm{KH}_{2} \mathrm{PO}_{4}, \mathrm{pH} 5.7$. The eluting compounds were detected at $254 \mathrm{~nm}$.

Identification of the peaks in the HPLC effluents were made on the basis of retention times. The retention times were compared with retention times of known pure standards that were measured routinely after every 4 th sample. Primarily, the peak height ratios at 254 versus $280 \mathrm{~nm}$ were measured for all four body fluids. Small changes in retention times or double peaks were checked by coelution with known pure standards. This was especially necessary at low xanthine concentrations.

Quantification of peaks was done by peak height ratios. All pure standards used for the HPLC were obtained from Sigma Chemical Co., St. Louis, MO.

Uric acid was measured on an RA-1000 (Technicon Instruments, Tarrytown, NY), automatic blood analyzer.

Statistics. Results are given as mean \pm SD. Wilcoxon's twotailed rank test was applied for testing the significance of differences between comparable groups. A $p$ value $<0.05$ was considered statistically significant.

\section{RESULTS}

Blood gases and mean arterial pressure. Table 1 shows the arterial $\mathrm{PaO}_{2}, \mathrm{O}_{2}$ saturation, and mean arterial blood pressure in the four groups of pigs. There were no differences between the groups before the start of hypoxemia. In the animals with the two most severe degrees of hypoxemia, there was an initial increase in blood pressure at the start of the hypoxemia, lasting for about $1 \mathrm{~h}$. The blood pressure in both these groups then gradually declined toward zero in the terminal phase, as previously described (13). No significant changes in the mean $\mathrm{PaCO}_{2}$ were found in any group.

Hypoxanthine, xanthine, and uric acid in CSF. The mean concentrations of hypoxanthine in the CSF of the pigs before the start of the hypoxemia was $15.8 \pm 4.1 \mu \mathrm{mol} / \mathrm{L}$, with no difference between the four groups. The changes between prehypoxemic, basal values and the values found during the hypoxemia and at death for groups 1 and 2 are illustrated in Figure $1 a$ and $b$, respectively. In these groups, there was a linear increase in CSF hypoxanthine concentrations reaching a maximum at death of $39.3 \pm 6.2 \mu \mathrm{mol} / \mathrm{L}$ in group $1(p<0.02$ compared with basal values) and $42.9 \pm 20.8 \mu \mathrm{mol} / \mathrm{L}(p<0.02)$ in group 2 . There was no difference at the time of death between groups 1 and 2 . In the two other groups, there was no significant change in the hypoxanthine concentration in the CSF (results not shown).

The mean xanthine concentration in the CSF of all pigs was $4.0 \pm 0.8 \mu \mathrm{mol} / \mathrm{L}$ before hypoxemia. In groups 1 and 2 , there were linear increases to $10.6 \pm 4.8 \mu \mathrm{mol} / \mathrm{L}(p<0.02)$ and 13.3 $\pm 5.5 \mu \mathrm{mol} / \mathrm{L}(p<0.02)$, respectively, at the time of death (Fig. $2)$, whereas the concentrations remained unchanged in the other two groups. There was no difference between the final concentrations of xanthine in groups 1 and 2 .

The mean uric acid concentration in the CSF in groups 1 and 2 was $2.9 \pm 2.8 \mu \mathrm{mol} / \mathrm{L}$ before hypoxemia, increasing to $11.6 \pm$

Table 1. Blood gases, arterial oxygen saturation, and mean arterial blood pressure before and during induced hypoxemia in four groups of pigs ventilated with 8 (group 1), 11 (group 2), 14 (group 3 ), and $21 \%$ oxygen (group 4 )*

\begin{tabular}{|c|c|c|c|c|c|}
\hline & $\mathrm{O}_{2} \%$ & $\begin{array}{c}\text { Before } \\
\text { hypoxemia }\end{array}$ & $\begin{array}{c}5 \text { min } \\
\text { hypoxemia }\end{array}$ & $\begin{array}{c}60 \mathrm{~min} \\
\text { hypoxemia }\end{array}$ & $\begin{array}{l}\text { Last sample } \\
\text { before death }\end{array}$ \\
\hline $\begin{array}{l}\mathrm{PaO}_{2} \\
\quad(\mathrm{kPa})\end{array}$ & $\begin{array}{r}8 \\
11 \\
14 \\
21\end{array}$ & $\begin{array}{l}11.6 \pm 1.2 \\
10.8 \pm 1.0 \\
13.0 \pm 0.8 \\
11.5 \pm 2.6\end{array}$ & $\begin{array}{l}2.8 \pm 0.4 \\
4.5 \pm 1.0 \\
6.2 \pm 1.1\end{array}$ & $\begin{array}{l}2.6 \pm 0.1 \\
3.5 \pm 0.7 \\
5.0 \pm 0.8\end{array}$ & $\begin{array}{r}2.9 \pm 0.5 \\
3.5 \pm 0.4 \\
4.5 \pm 0.9 \\
10.7 \pm 0.6\end{array}$ \\
\hline $\begin{array}{r}\mathrm{Sat} \mathrm{O}_{2} \\
(\%)\end{array}$ & $\begin{array}{r}8 \\
11 \\
14 \\
21\end{array}$ & $\begin{array}{l}97.6 \pm 0.9 \\
97.3 \pm 1.0 \\
98.1 \pm 0.4 \\
96.8 \pm 2.2\end{array}$ & $\begin{array}{l}42.1 \pm 10.0 \\
73.5 \pm 12.1 \\
85.0 \pm 6.3\end{array}$ & $\begin{array}{l}31.4 \pm 4.2 \\
53.0 \pm 15.4 \\
74.8 \pm 7.7\end{array}$ & $\begin{array}{l}25.4 \pm 7.6 \\
41.4 \pm 9.3 \\
70.1 \pm 10.9 \\
97.3 \pm 0.6\end{array}$ \\
\hline $\begin{array}{l}\text { MABP } \\
\text { (mm Hg) }\end{array}$ & $\begin{array}{r}8 \\
11 \\
14 \\
21\end{array}$ & $\begin{array}{l}105 \pm 15 \\
120 \pm 15 \\
115 \pm 30 \\
110 \pm 25\end{array}$ & $\begin{array}{l}135 \pm 20 \\
135 \pm 20 \\
120 \pm 35\end{array}$ & $\begin{array}{l}115 \pm 20 \\
140 \pm 20 \\
105 \pm 25\end{array}$ & $\begin{array}{r}30 \pm 10 \\
50 \pm 20 \\
115 \pm 30 \\
115 \pm 10\end{array}$ \\
\hline
\end{tabular}

* Figures given are mean $\pm \mathrm{SD} . \mathrm{PaO}_{2}$, arterial $\mathrm{O}_{2}$ tension; Sat $\mathrm{O}_{2}$, arterial $\mathrm{O}_{2}$ saturation; MABP, mean arterial blood pressure. 
A

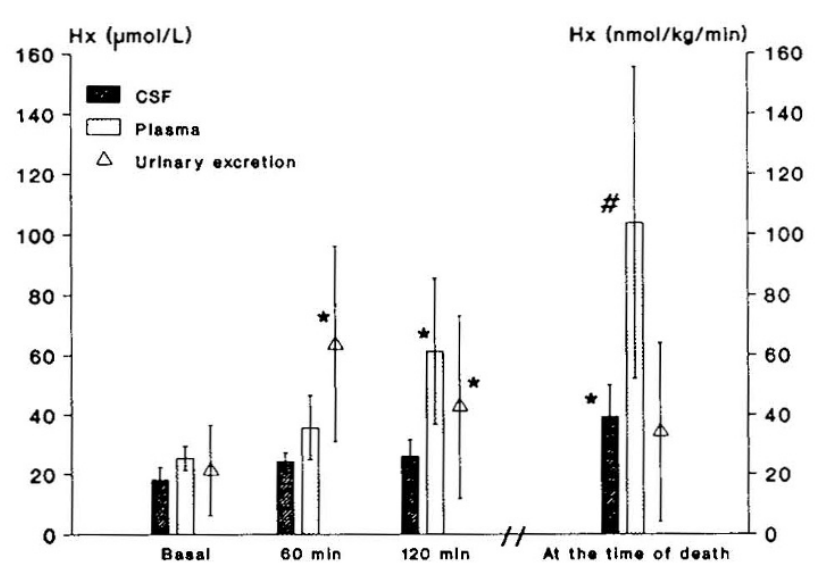

B

Group 2 (FiO2 $\cdot 0.11)$

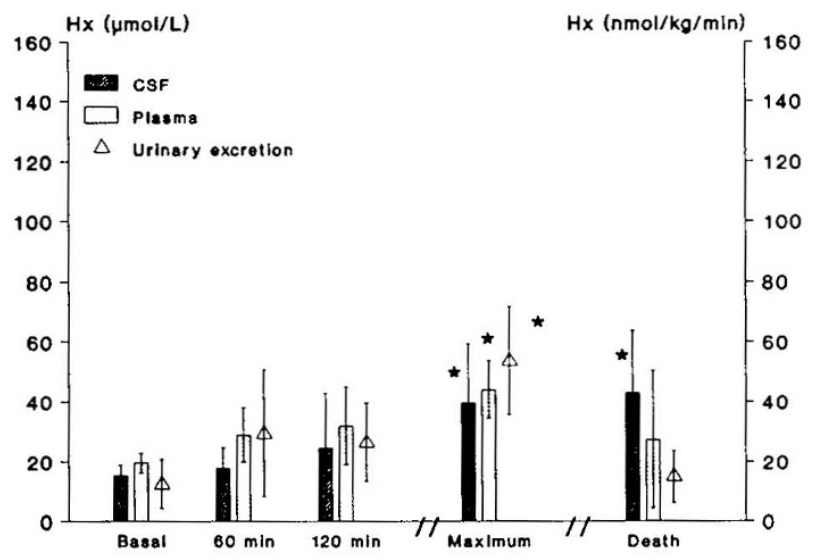

Fig. 1. Concentrations in the CSF and plasma and urinary excretion of hypoxanthine. Hypoxanthine $(H x)$ concentrations $(\mu \mathrm{mol} / \mathrm{L})$ and urinary excretion $(\mathrm{nmol} / \mathrm{kg} / \mathrm{min}$ ) were measured before hypoxemia (basal), after 60 and $120 \mathrm{~min}$ of hypoxemia, and at the time of death in hypoxemic pigs. $A$, Group $1, n=7, \mathrm{FiO}_{2}=0.08 ; B$, group $2, n=7, \mathrm{FiO}_{2}$ $=0.11$. The maximum is the highest concentration recorded during the hypoxemic period in the live animal. The maximal concentrations were not necessarily reached at the same time for the three body fluids during the hypoxemic period. ${ }^{*} p<0.02$ compared with values before hypoxemia. $\# p<0.05$ compared with values before hypoxemia.

$11.7 \mu \mathrm{mol} / \mathrm{L}$ at the time of death in group $1(p<0.05)$, and to $16.3 \pm 16.8 \mu \mathrm{mol} / \mathrm{L}$ at the time of death in group $2(p<0.02)$ There was no difference between the final concentrations of uric acid in groups 1 and 2 . Uric acid was not measured in groups 3 and 4.

Hypoxanthine, xanthine, and uric acid in plasma. The mean plasma concentration of hypoxanthine in the pigs was $21.8 \pm$ $4.4 \mu \mathrm{mol} / \mathrm{L}$ before the start of hypoxemia. There was no difference between the four groups. Figure $1 a$ illustrates the variation of plasma hypoxanthine in group 1 . In all the pigs in this group, plasma hypoxanthine increased significantly during hypoxemia. However, in one pig, the hypoxanthine concentration toward death fell below the starting value (start, $23 \mu \mathrm{mol} / \mathrm{L}$; maximum during hypoxemia, $39 \mu \mathrm{mol} / \mathrm{L}$; at time of death, $11 \mu \mathrm{mol} / \mathrm{L})$. In the other six pigs, hypoxanthine concentrations continued to increase up to the time of death, resulting in an average terminal value in the seven pigs of $103 \pm 51.7 \mu \mathrm{mol} / \mathrm{L}(p<0.05)$. Figure $1 b$ shows that the plasma concentration of hypoxanthine increased significantly in pigs breathing $11 \%$ oxygen (group 2 ) as well, reaching a mean maximum of $44.1 \pm 9.5 \mu \mathrm{mol} / \mathrm{L}(p<$ 0.02 ). However, also in this group, three of the pigs had a fall in concentrations terminally below the starting value or even to

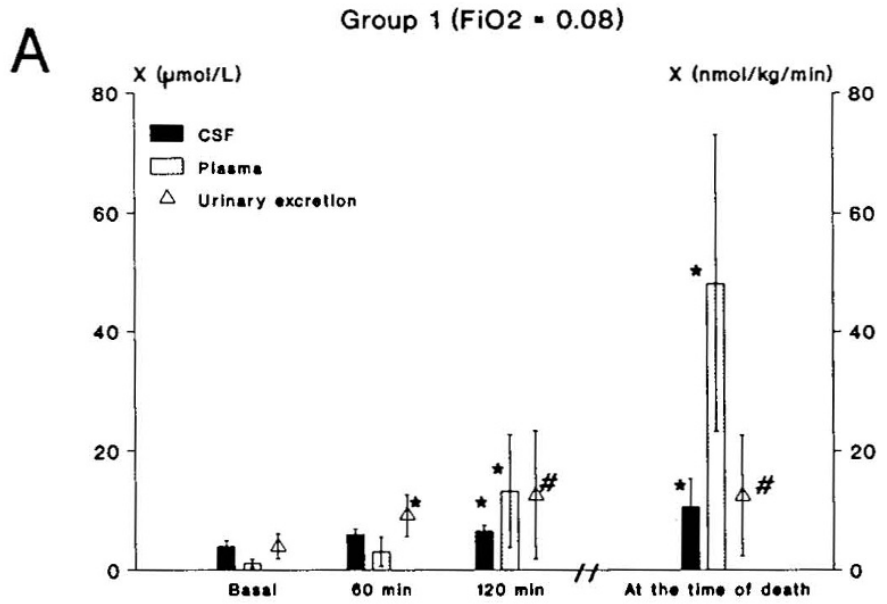

B

Group 2 (FiO2 -0.11$)$

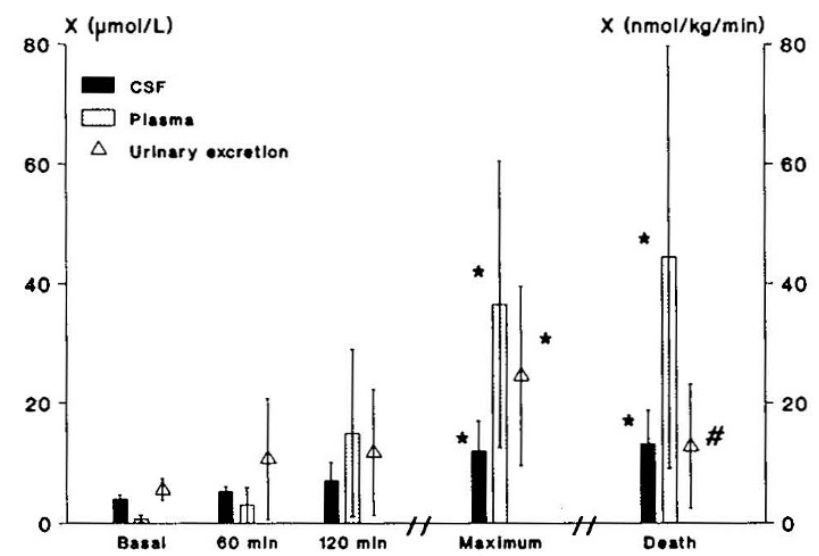

Fig. 2. Concentrations in the CSF and plasma and urinary excretion of xanthine. Xanthine $(X)$ concentrations $(\mu \mathrm{mol} / \mathrm{L})$ and urinary excretion $(\mathrm{nmol} / \mathrm{kg} / \mathrm{min}$ ) were measured before hypoxemia (basal), after 60 and $120 \mathrm{~min}$ of hypoxemia, and at the time of death in hypoxemic pigs. $A$, group 1, $n=7, \mathrm{FiO}_{2}=0.08 ; B$, group $2, n=8, \mathrm{FiO}_{2}=0.11$. The maximum is the highest concentration recorded during the hypoxemic period in the live animal. The maximal concentrations were not necessarily reached at the same time in the three body fluids during the hypoxemic period. ${ }^{*} p<0.02$ compared with values before hypoxemia. $\# p<0.05$ compared with values before hypoxemia.

zero, resulting in an average value at the time of death of $27.0 \pm$ $23 \mu \mathrm{mol} / \mathrm{L}$ (not statistically different from either the prehypoxemic value or the maximum value during hypoxemia). The plasma concentrations of hypoxanthine in the other two groups changed only marginally during the experiment (results not shown).

When relating all our measurements of plasma hypoxanthine to the actual $\mathrm{PaO}_{2}$ of the pigs, we found that the hypoxanthine concentration rose when the $\mathrm{PaO}_{2}$ was lower than approximately $4 \mathrm{kPa}$ (30 mm Hg) (Fig. 3).

The mean plasma concentration of xanthine was $0.7 \pm 0.7$ $\mu \mathrm{mol} / \mathrm{L}$ before the start of hypoxemia. There were no significant differences among the four groups. In group 1, plasma concentration of xanthine continued to rise in all seven pigs until death, with a terminal mean level of $48.1 \pm 24.9 \mu \mathrm{mol} / \mathrm{L},(p<0.02$ compared with prehypoxemic levels) (Fig. $2 a$ ). In group 2 (Fig. $2 b$ ), plasma xanthine concentrations increased until death in all but one pig, where the concentration fell to zero terminally, resulting in a mean concentration measured just after death of $44.4 \pm 37.0 \mu \mathrm{mol} / \mathrm{L}(p<0.02$ compared with basal levels). There was no difference between the terminal xanthine concentrations found in groups 1 and 2 . 


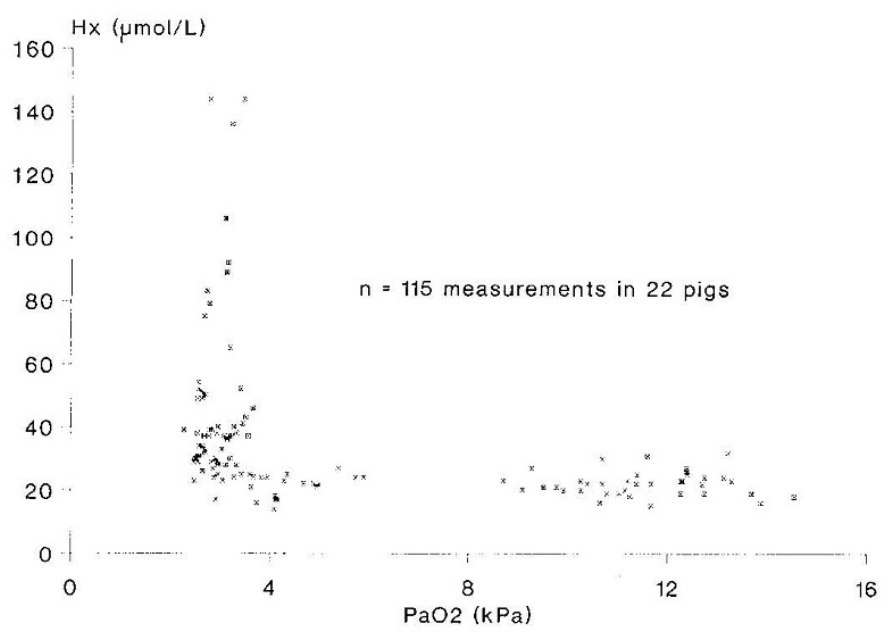

Fig. 3. Hypoxanthine concentrations in plasma in relation to $\mathrm{PaO}_{2}$ in pigs.

The mean plasma concentration of uric acid in groups 1 and 2 was $15.4 \pm 2.7 \mu \mathrm{mol} / \mathrm{L}$ before hypoxemia. The concentration of uric acid continued to rise in all pigs in these groups, even when hypoxanthine or xanthine concentrations fell, resulting in a maximum of $125 \pm 32 \mu \mathrm{mol} / \mathrm{L}$ at the time of death in group $1(p<0.02)$, and $208 \pm 148 \mu \mathrm{mol} / \mathrm{L}$ at the time of death in group $2(p<0.02)$. There was no difference between terminal uric acid concentrations found in groups 1 and 2 .

The maximum hypoxanthine concentrations were generally reached earlier in the hypoxemic period than the maximum xanthine concentrations.

When considering the total amount of hypoxanthine and xanthine in plasma, we found a starting value of $25.5 \pm 3.8$ $\mu \mathrm{mol} / \mathrm{L}$ and a terminal value of $151.7 \pm 50.0 \mu \mathrm{mol} / \mathrm{L}$ in group 1 ( $p<0.02$ compared with basal values) and, in group 2, a basal value of $20.3 \pm 3.4 \mu \mathrm{mol} / \mathrm{L}$, a maximum value during hypoxemia of $80.7 \pm 31.3 \mu \mathrm{mol} / \mathrm{L}$ ( $p<0.02$ compared with basal values), and a terminal value of $68.0 \pm 41.3 \mu \mathrm{mol} / \mathrm{L},(p<0.05$ compared with basal value, but NS compared with maximum values). The terminal total amount of hypoxanthine and xanthine in plasma was significantly higher in group 1 than in group $2(p<0.05)$.

In groups 3 and 4 , there was no significant increase either of hypoxanthine or of xanthine in plasma during the experiments (results not shown). In these groups, uric acid was not measured.

Hypoxanthine and xanthine in urine. The mean basal excretion of hypoxanthine in the urine was $17 \pm 12 \mathrm{nmol} / \mathrm{kg} / \mathrm{min}$. There were no significant differences between the groups. In group 1, during hypoxemia there was a nearly 5-fold increase in the amount of hypoxanthine excreted in the urine, reaching a mean maximum of $87 \pm 27 \mathrm{nmol} / \mathrm{kg} / \mathrm{min}(p<0.02)$. In the last measurements before death, the mean values had declined toward basal levels (Fig. 1a). The urinary excretion of xanthine in this group followed the same pattern described for hypoxanthine (Fig. 2a). Figure $1 b$ shows, in addition, the urinary excretion of hypoxanthine in group 2 . In this group, there was, compared with basal values, a nearly 3 -fold increase in the rate of hypoxanthine excretion, reaching a mean maximum value of $54 \pm 18$ $\mathrm{nmol} / \mathrm{kg} / \mathrm{min}(p<0.02)$. In the last measurement before death, the mean values had dropped significantly, reaching levels recorded before hypoxemia, $15 \pm 9 \mathrm{nmol} / \mathrm{kg} / \mathrm{min}$. In the hypoxemic animals breathing $14 \%$ oxygen (group 3), there was a 2fold increase in the rate of hypoxanthine excretion, reaching a mean maximum value of $33 \pm 15 \mathrm{nmol} / \mathrm{kg} / \mathrm{min}$, but this increase was not statistically significant.

The urinary excretion of xanthine in group 2 followed the same pattern as that of hypoxanthine (Fig. $2 b$ ).

There was no significant increase in urinary xanthine excretion in the pigs breathing $14 \%$ oxygen.
In the control group, neither hypoxanthine nor xanthine excretion changed.

\section{DISCUSSION}

We found a higher basal concentration of hypoxanthine in CSF of pigs $(15.8 \mu \mathrm{mol} / \mathrm{L})$ than has been reported in normal human newborns, children, and adults $(3.5 \mu \mathrm{mol} / \mathrm{L})(14)$. During hypoxemia in both groups 1 and 2, the hypoxanthine concentrations increased about 2.5-fold in the CSF. Nevertheless, when comparing CSF concentrations with plasma concentrations, we found a different pattern during the two degrees of hypoxemia. In group 2 (the milder degree), at death the concentrations of hypoxanthine in the CSF and in the plasma were about equal. In comparison, when the pigs died after the most severe hypoxemia (group 1), the plasma level of hypoxanthine was found to be two to three times higher than the CSF level. This indicates that hypoxanthine in the CSF is regulated by a different mechanism than plasma hypoxanthine. An active transport system in the choroid plexus for hypoxanthine has been found (15), and presumed to act to remove hypoxanthine from the CSF. However, Spector (16) stated that the directionality, if any, for transport by that system is not known. From our results, we cannot say whether hypoxanthine is transported from the CSF to blood or vice versa. The differences between the two body fluids during hypoxemia became even more obvious when we looked at the changes in xanthine and uric acid concentrations. In the CSF, xanthine increased about three-fold, whereas in the plasma we found a 60 - to 70 -fold increase in concentrations. The increases in uric acid concentrations were less marked, about five-fold in the CSF and 14-fold in the plasma.

The concentrations measured in the CSF after hypoxemia correspond well with the findings of Harkness and Lund (14) in children after hypoxia. In their report, however, there is no mention of blood gases or the duration of the hypoxic episodes. Furthermore, their measurements were done 1 to $2 \mathrm{~d}$ after the hypoxic episode, so a direct comparison is difficult.

In several pigs from the two most severely hypoxemic groups, a fall in both plasma hypoxanthine and xanthine concentration after an initial peak was found, comparable to data we previously have published from hypoxemic dogs (17). In the dog, there is, however, a large lung metabolism of hypoxanthine and xanthine to uric acid due to the presence of xanthine oxidase (EC 1.1.3.22) (18). Until now, we believed that this enzyme was not present to any extent in the pig lungs (9). If xanthine oxidase is present in the pig lungs, or if xanthine oxidase is liberated into the circulation by a severely hypoxemic liver, this species may have the capacity to clear hypoxanthine from the circulation even during profound hypoxemia. This may also explain the different pattern found between CSF and plasma, with a steady increase in CSF, whereas in some of the pigs hypoxanthine fell in plasma towards the end of the experiments. Another possible explanation may be the presence of the enzyme liver aldehyde oxidase (EC 1.2.3.1). In the rabbit, this enzyme has the capability to catalyze the conversion of hypoxanthine to xanthine, but not the conversion of xanthine to uric acid (19). Concentrations of hypoxanthine and xanthine may also be altered independently, inasmuch as xanthine can arise from breakdown of guanine. The finding of approximately equal xanthine concentrations at the time of death in both CSF and plasma in both group 1 and group 2 may indicate that under hypoxemic conditions only a certain limited amount of hypoxanthine will be converted to xanthine.

Urinary excretion, especially of hypoxanthine, might be a sensitive method for studying adenine nucleotide catabolism in man. There is a high renal clearance of hypoxanthine (20), and acute changes in plasma hypoxanthine concentrations may therefore be reflected in the urine. The renal clearance of xanthine, however, can exceed creatinine clearance, suggesting a tubular origin for at least some of the excreted xanthine (10). Urinary xanthine will therefore not reflect plasma xanthine as sensitively 
as urinary hypoxanthine will reflect plasma hypoxanthine. In normal human subjects, there are only a few reports on renal transport/urinary excretion of hypoxanthine and xanthine (10, $21)$. In the two most severely hypoxemic groups, the pigs increased their urinary excretion of hypoxanthine and xanthine shortly after the hypoxemia was initiated. We found, however, a tremendous drop in urinary hypoxanthine excretion toward death, but these animals had at that time a fall in blood pressure that probably resulted in reduced or even ceased renal perfusion.

In summary, CSF hypoxanthine reflects hypoxemia, but it seems to be partly independent on the degree and duration. The plasma hypoxanthine concentration reflects the degree of hypoxemia more sensitively in severe than in mild hypoxemia, but the duration of hypoxemia seems to play a smaller part than the degree. There is no clear relationship between concentrations of hypoxanthine found in the CSF and concentrations found in plasma. If the hypoxemia leads to death, postmortem measurements of hypoxanthine in the vitreous humor may give an indication of the duration of hypoxemia ante-mortem (22). Urinary concentrations of hypoxanthine may be a sensitive method of studying adenine nucleotide catabolism, but a meaningful result can only be obtained if the diuresis is known.

Acknowledgment. The authors thank the Department of Clinical Chemistry at the National Hospital for performing the uric acid analyses.

\section{REFERENCES}

1. Saugstad OD 1988 Hypoxanthine as an indicator of hypoxia: its role in health and disease through free radical production. Pediatr Res 23:143-150

2. Saugstad OD 1975 Hypoxanthine as a measurement of hypoxia. Pediatr Res 9:158-161

3. Thiringer K 1983 Cord plasma hypoxanthine as a measure of fetal hypoxia. Acta Paediatr Scand 72:231-237

4. Pietz J, Guttenberg N, Gluck I 1988 Hypoxanthine: a marker for asphyxia. Obstet Gynecol 72:762-766

5. Ruth V, Fyhrquist F, Clemons G, Raivio KO 1988 Cord plasma vasopressin, erythropoietin and hypoxanthine as indices of asphyxia at birth. Pediatr Res 24:490-494

6. Meberg A, Saugstad OD 1978 Hypoxanthine in cerebrospinal fluid in children. Scand J Clin Lab Invest 38:437-440

7. Manzke H, Staemmler W 1981 Oxypurine concentrations in CSF in children with different diseases of the nervous sytem. Neuropediatrics 12:209-214

8. Manzke H, Dörner K, Grünitz J 1977 Urinary hypoxanthine, xanthine, and uric acid in newborn infants with perinatal complications. Acta Paediat Scand 66:713-717

9. Saugstad OD, Aasen AO 1980 Plasma hypoxanthine concentrations in pigs. A prognostic aid in hypoxia. Eur Surg Res 12:123-129

10. Harkness RA 1988 Hypoxanthine, xanthine and uridine in body fluids, indicators of ATP deletion. J Chromatogr 429:255-278

11. Wung WE, Howell SB 1980 Simultaneous liquid chromatography of 5-fluorouracil, uridine, hypoxanthine, xanthine, uric acid, allopurinol and oxypurino in plasma. Clin Chem 26:1704-1708

12. Simmonds RJ, Harkness RA 1981 High-performance liquid chromatographic methods for base and nucleoside analysis in extracellular fluids and in cells. J Chromatogr 226:369--381

13. Saugstad OD, Aasen AO, Hetland $\varnothing 1978$ Plasma hypoxanthine levels in pigs during acute hypoxemia. Eur Surg Res 10:314-321

14. Harkness RA, Lund RJ 1983 Cerebrospinal fluid concentrations of hypoxanthine, xanthine, uridine and inosine: high concentrations of the ATP metabolite, hypoxanthine, after hypoxia. J Clin Pathol 36:1-8

15. Nelson JA, Cserr HF 1976 Transport and metabolism of purines by isolated choroid plexus, liver and brain in the spiny dogfish, Squalus acanthias. Comp Biochem Physiol [B] 53:371-377

16. Spector R 1987 Hypoxanthine transport through the blood-brain barrier. Neurochem Res 12:791-796

17. Saugstad OD, B $\varnothing$ G, Østrem T, Aasen AO 1977 Hypoxanthine levels of the plasma during hypoxemia in dogs. Eur Surg Res 9:23-33

18. Al-Khalidi UAS, Chaglassian TH 1965 The species distribution of xanthine oxidase. Biochem J 97:318-320

19. Krenitsky TA, Neil SH, Elion GB, Hitchings GH 1972 A comparison of the specificities of xanthine oxidase and aldehyde oxidase. Arch Biochem Biophys 150:585-599

20. Harkness RA, Coade, SB, Walton KR, Wright D 1983 Xanthine oxidase deficiency and "Dalmatian" hypouricaemia: incidence and effect of exercise. J Inherited Metab Dis 6:114-120

21. Kaneko K, Fujimori S, Itoh $\mathrm{H}$, Nakayama $\mathrm{Y}$, Oyama $\mathrm{H}$, Kanbayashi $T$, Miyashita H, Akaoka I 1988 Renal handling of hypoxanthine and xanthine in normal subjects and in four cases of idiopathic renal hypouricemia. J Rheumatol 15:325-330

22. Poulsen JP, Rognum TO, Øyasæter S, Saugstad OD 1990 Changes in oxypurine concentrations in vitreous humor of pigs during hypoxemia and post-mortem. Pediatr Res 28:482-484 